\title{
Agressor sexual de crianças e adolescentes: uma discussão sobre o gênero dos participantes na literatura
}

\author{
Sexual abuser of children and adolescents: a discussion on the gender of participants in the \\ literature
}

Agresor sexual de niños y adolescentes: una discusión sobre el género de los participantes en la literatura

\author{
Daniela Castro dos Reis* \\ Arthur Aliverti Saltori de Barros ${ }^{* *}$ \\ Lilia Iêda Chaves Cavalcante
}

\begin{abstract}
Resumo
As pesquisas sobre violência sexual têm deixado em aberto várias questões, sobretudo estudos voltados para a condição biopsicossocial do agressor. Este trabalho teve como objetivo mapear exploratória e sistematicamente a literatura sobre os agressores sexuais de crianças e adolescentes, discutindo questôes de gênero. Realizou-se o levantamento pelo Periódico CAPES, utilizando descritores em português: agressor sexual, pedófilo, aliciador, abusador sexual, traficante sexual, perpetrador sexual, angariador sexual, sequestrador sexual, estuprador e molestador sexual. Identificou-se 1.303 artigos, dos quais 1.071 foram descartados, 82 repetidos e 150 selecionados. Os critérios de inclusão (artigos científicos completos, independentes do ano, em todas as áreas e bases do periódico, nos idiomas português, inglês e espanhol) e de exclusão (literatura cinzenta, violência sexual em adultos, estudos em animais não humanos). Os dados mostraram que os estudos se concentraram nas vítimas, sobretudo no gênero feminino. Nos trabalhos com agressores, além da baixa publicação científica, a ênfase estava no gênero masculino.
\end{abstract}

Palavras-chave: Agressão. Violência sexual. Criança. Adolescente.

\footnotetext{
Texto recebido em setembro 2013 e aprovado para publicação em novembro de 2014.

Doutoranda e mestra pelo Programa de Pós-Graduação em Teoria e Pesquisa do Comportamento da Universidade Federal do Pará (PPGTPC/UFPA), docente da Universidade Federal Rural da Amazônia, psicóloga. Endereço: Avenida Milton Ribeiro, Lote 36, Q. 78 - Bairro Parque dos Carajás, Parauapebas-PA, Brasil. CEP: 68515-000. E-mail: danireispara@yahoo.com.br.

* Graduando em Psicologia da Universidade Federal do Pará. Endereço: Avenida Milton Ribeiro, Lote 36, Q. 78 - Bairro Parque dos Carajás, Parauapebas-PA, Brasil. CEP: 68515-000. E-mail: arthuraliverti@hotmail.com.

${ }^{* * *}$ Docente do PPGTPC/UFPA e da Faculdade de Serviço Social (FASS/UFPA). Endereço: Avenida Cabanos, 1922, ap. 2300. Edifício Piazza Venezzia - Batista Campos, Belém-PA, Brasil. CEP 66033-000. E-mail: liliaccavalcante@gmail.com.
} 


\begin{abstract}
Research on sexual violence have left open several questions, particularly studies on the biopsychosocial condition of the offender. The research aimed to explore systematically the literature on sexual offenders of children and adolescents, discussing gender issues. The survey was conducted by the Journal CAPES, using descriptors in Portuguese: sexual aggressor, pedophile, enticer, sexual abuser, sexual trafficker, sexual perpetrator, sexual recruiter, sexual kidnapper, rapist and sex offender. We identified 1303 articles, of which 1071 were discarded, 82 repeated and 150 selected. Inclusion criteria (complete scientific articles, independent of the year, in all areas and bases of the journal, in Portuguese, English and Spanish) and exclusion (gray literature, sexual violence in adults, studies in nonhuman animals). The data showed that the studies have focused on the victims, especially in females. In the works with offenders and the low scientific publication, the emphasis was on males.
\end{abstract}

Keywords: Aggression. Sexual violence. Child. Adolescent.

\title{
Resumen
}

La investigación sobre la violencia sexual ha dejado abiertas varias cuestiones, en particular estudios sobre la condición biopsicosocial del agresor. El objetivo del estudio fue analizar de forma sistemática la literatura sobre los agresores sexuales de niños y adolescentes, discutiendo cuestiones de género. El estudio fue realizado por la publicación CAPES, utilizando descriptores en portugués: agresor sexual, pedófilo, inductor, abusador sexual, traficante sexual, perpetrador sexual, persona que recluta las víctimas de delitos sexuales, secuestrador sexual, violador y acosador sexual. Se identificaron 1303 artículos, 1071 fueron descartados, 82 repetidos y 150 seleccionados. Los criterios de inclusión (artículos científicos completos, independientes del año, en todas las áreas y bases de la publicación, en los idiomas portugués, inglés y español) y de exclusión (literatura gris, violencia sexual en adultos, estudios en animales no humanos). Los datos mostraron que los estudios se concentraron en las víctimas, especialmente en el género femenino. En los estudios con agresores, además de hacer constar la escasa publicación científica, el énfasis estaba en el género masculino.

Palabras clave: Agresión. Violencia sexual. Niño. Adolescente. 
A violência sexual contra crianças e adolescentes acompanha a trajetória $\Delta$ histórica da humanidade, manifestando-se de múltiplas formas, em Idiferentes épocas e contextos sociais, conforme concepções e práticas culturais vigentes (Costa et al., 2007; Krug, Mercy, Dahlberg, Zwi \& Lozano, 2002). Para se entenderem a configuração histórica e os significados sociais que fazem da violência sexual um fenômeno tão antigo quanto atual, torna-se necessário compreender os comportamentos que a definem como tal, quais as suas formas mais comuns de expressão no cotidiano de famílias e instituições bem como os sujeitos envolvidos nessas relações abusivas.

A preocupação com as várias faces da violência sexual contra crianças e adolescentes e com os riscos potenciais para o desenvolvimento, nessa fase da vida e nos anos posteriores, pode ser percebida pela divulgação de artigos que têm sido publicados em todo o mundo, por meio dos quais são abordadas as sequelas decorrentes das diversas formas de abuso (Aded, Dalcin, Moraes \& Cavalcanti, 2006). Todavia as pesquisas têm deixado algumas lacunas quanto às várias questões que parecem ter relação direta com a efetividade e eficácia dos resultados das ações no enfrentamento à violência sexual, sobretudo estudos voltados para a discussão da condição biológica, psicológica e social do agressor, ou seja, o perfil da pessoa responsável por perpetrar a violência.

Em termos internacionais, foi observado nos trabalhos de Allard-Dansereau, Haley, Hamane e Bernard-Bonnin (1997), Brewster et al. (1998), Craissatti e McClurg (1997) que, hoje, há uma produção consistente, ampla e diversificada sobre a condição biopsicossocial dos agressores sexuais. Em direção oposta, no Brasil, a produção científica sobre o agressor sexual de crianças e adolescentes ainda é incipiente quando comparada ao volume de estudos em âmbito mundial.

Pode-se dizer que, no Brasil, somente a partir de meados do século XX, sobretudo na última década, a atenção do público em geral e da comunidade em particular concentrou-se no tema da violência sexual contra crianças e adolescentes, realçando, nesse cenário, a figura do agressor. Em razão disso, era de se esperar que a discussão específica sobre a condição biopsicossocial do agressor pudesse ter progredido nos últimos anos, aproximando-se até mesmo em número de pesquisa e em qualidade das investigaçóes voltadas às vítimas, o que permitiria uma compreensão maior do seu sentido e das possibilidades de intervenção governamental nessa problemática.

Entretanto essa expectativa não se concretizou e continua a exigir pesquisas científicas adequadas à realidade e que ofereçam fundamentos teóricos capazes de sustentar uma discussão consistente sobre o agressor sexual de crianças e adolescentes, e que permitam a implantação de ações interdisciplinares 
e multidisciplinares com vista à minimização da violência sexual e, consequentemente, à melhor qualidade de vida dos atores envolvidos (Barbosa, Macedo, Melo \& Piola, 2010; Martins \& Jorge, 2010; Pereira, Lira, Xavier \& Vieira, 2007).

Abordar questôes relacionadas ao agressor sexual de crianças e adolescentes requer estudos em diversas áreas, pois envolve uma dimensão ampla, com uma gama de discussões e um elevado grau de complexidade. Teoricamente, podese dizer que há uma produção literária embrionária e emergente nas Ciências Comportamentais (Almeida, 2003) e na Psicologia do Desenvolvimento Humano (Morais, Santos, Moura, Vaz \& Koller, 2007), fazendo com que o assunto em epígrafe comece a ganhar força hoje.

Nesse sentido, a discussão sobre o processo de socialização primária e a trajetória do desenvolvimento do agressor sexual de crianças e adolescentes constituem-se temas marcados pela complexidade e cercado, ainda, de tabus. No exemplo brasileiro, a figura do agressor sexual tem sido pouco explorada em pesquisas realizadas no País. Assim, pouco se sabe acerca das diversidades regionais que norteiam o fenômeno, dos aspectos societários e das questóes de gênero que tangenciam a investigação. Mesmo as discussões mais recentes têm deixado, por vezes, de levar em conta os diferentes contextos em que ocorreu a manifestação de tal violência. $\mathrm{O}$ tema traz, ainda, um ranço histórico e social dos múltiplos preconceitos que marcaram a pesquisa sociológica, antropológica, psicológica, entre outras áreas do conhecimento (Morais et al., 2007; Moura, 2007).

Então, por ser um tema pouco explorado cientificamente, a literatura disponível ainda não consegue apontar as diferenças pautadas nas diversidades contextuais, societárias e de gênero que cercam o assunto, principalmente na definição dos papéis de vítima e de agressor sexual. Especificamente sobre identidade e relações de gênero, este trabalho adota o conceito de Dragowski, Rio e Sandigorsky (2011) que atribuem a esse termo regras culturais, ideologias e comportamentos esperados para indivíduos de fenótipos e características sexuais diferentes. Dessa forma, pode-se dizer que, por ser um tema com ampla carga ideológica, muito das concepçôes sociais de gênero pode direcionar as pesquisas científicas, assumindo, mesmo que de maneira disfarçada, os estigmas sociais que estão postos.

A retórica de que o gênero masculino é violento por si só é estigmatizante, a ideia de que o comportamento agressivo é, essencialmente, masculino costuma ser reforçada na coletividade e em determinadas sociedades. No caso do Brasil, o homem carrega uma herança histórica aliada aos estereótipos sociais 
centrados na dominação masculina sobre a mulher. Não há como negar que, historicamente, os homens estruturaram o poder patriarcal de dominação sobre o gênero feminino, em que a organização social da propriedade, dos poderes, do mando, dos territórios, das condutas próprias do poder sobre os corpos, sobre a sexualidade e os comportamentos sexuais se sobrepôs ao gênero feminino. Isso contribui até hoje para que o homem seja visto como ser violento, agressivo e dominador na relação com as mulheres (Faleiros, 2007), porém alguns homens assumem mais o papel da dominação e da punição violenta (psicológica, social, física e sexual) como enfatiza Phebo (2007). Logo, cada vez mais a violência é reforçada como um tema eminentemente masculino, enfatizando-se o homem como agressor.

No outro lado dessa discussão está a mulher que, comumente, não é percebida como agressora (Huss, 2011), pois os papéis sociais atribuídos ao gênero feminino representam-na como cuidadora, amorosa, afetiva, indefesa e frágil, e acabam por camuflar a violência perpetrada por ela. Diante de qualquer ato de violência contra criança e adolescente, muitas vezes, o tabu conduz a justificar-se a agressão como práticas educativas parentais (Weber, Viezzer \& Brandenburg, 2004). Todos esses aspectos podem contribuir para a ausência de pesquisas com mulheres agressoras, inclusive e principalmente, as sexuais. Segundo Williams (2012), com base em estudos da literatura norte-americana, a parcela de mulheres agressoras é inferior a $5 \%$ da população. Também para Christiansen e Thyer (2002), a prevalência dos crimes sexuais praticados por mulheres é desconhecida, com estimativas que variam de $2 \%$ a $5 \%$ de todos os condenados sexuais sendo mulheres. Ainda para Williams (2012), isso se deve porque o assunto é um tabu, extremamente privado, dificultando, assim, as pesquisas com agressoras do sexo feminino, aspecto igualmente observado por Huss (2011) que afirma existir relativamente pouca pesquisa com essa população.

Se, por um lado, a produção de trabalhos científicos sobre o agressor sexual de crianças e adolescentes ainda é incipiente e acanhada, o mesmo não se pode dizer das pesquisas sobre a condição biopsicossocial das vítimas, que tem sido amplamente difundida e estudada. Para Costa, Cordeiro, Kalil e Brandão (2007), Habigzang, Koller, Azevedo e Machado (2005), Marques (2005), Serafim, Saff, Rigonatti, Casoy e Barros (2009) talvez isso se deva em função da maior visibilidade do fenômeno social e da sua importância, hoje, na permanência da violação de direito. Estudos sobre as vítimas de violência sexual tentam compreender os vários meandros que circundam a sua condição de violação, sejam os aspectos biopsicossociais de crianças e adolescentes vítimas, seja sobre o levantamento do perfil sociodemográfico destas, ou, ainda, sobre a dinâmica familiar diante da violência sexual, os diversos contextos onde as vítimas vivem 
e têm sido expostas, além das diferentes estratégias de atendimento (Costa et al., 2007).

Apesar de haver uma ampla produção sobre as vítimas, nota-se também a distinção de gênero, com ênfase em pesquisas no gênero feminino (JuniorPinto, 2005). Os dados epidemiológicos sugerem que a violência sexual é mais frequente em meninas do que em meninos (Hohendorff, Bavaresco, Habgzang \& Koller, 2012). Estima-se que 1 em cada 4 meninas e 1 em cada 6 meninos tenham experimentado alguma forma de abuso sexual na infância ou adolescência (Hohendorff et al., 2012). As razões são diversas para essa desproporção e devem ser consideradas dentro dos estudos sobre a temática.

A crença de que o gênero feminino necessita de maior proteção do que o sexo masculino é percebida como um estigma marcante na sociedade ocidental. Para Junior-Pinto (2005), parece que há, no imaginário das pessoas, a ideia de que meninos e homens não são vitimados sexualmente e que esse é um problema essencialmente para as meninas. Para Assis (2007), a diferença está na forma da criação, pois as meninas têm mais apoio social do que os meninos, resultado de uma socialização mais protegida, o que acaba marginalizando o sexo masculino. Ainda para o autor, há outra diferença, as meninas são ensinadas a falar, enquanto os meninos externam por meio da agressão o comportamento. Eles são ensinados a punir outras pessoas, enquanto as garotas são orientadas a manter suas dores dentro de si ou expressá-las. Por isso há um volume maior de trabalhos com as vítimas do gênero feminino, haja vista as meninas revelarem a violência aos seus pares e, ou, responsáveis, promovendo maiores chances de resolução da situação e maior frequência de notificação.

Por outro lado, no caso de estudo com meninos vítimas de agressão sexual, apesar de ser um tema que começa a ascender, Junior-Pinto (2005) garante que eles sofrem ainda marginalização no meio científico, dificultando estudos com esse público. $\mathrm{O}$ autor acredita haver uma ideologia, não só no senso comum, mas também no meio das teorias científicas, pelo que meninos estão imunes a esse tipo de violência, por causa da sua "força de macho". Além disso, a revelação do ato por parte do menino poderá levá-lo a uma humilhação social, sofrendo estigmas e levando a outros processos sociais humilhantes, o que pode induzir ciclos discriminatórios.

A discriminação social que alguns meninos sofrem em relevar o abuso sexual e a crença de que o menino, por ser homem, tem um lado mais forte, logo não desenvolve trauma, faz com que o preconceito se torne cada vez mais arraigado no seio da sociedade. $\mathrm{O}$ medo, a vergonha e o descrédito são também razões para não se pedir ajuda (Junior-Pinto, 2005; Phebo, 2007), o que pode justificar 
a baixa notificação quando comparada com meninas. Para Assis (2007), a exclusão se manifesta, ainda, na dimensão das representaçôes sociais, acrescida pela invisibilidade da pobreza, da raça, da inserção infracional e do gênero, repercutindo na produção científica de maneira geral.

Considera-se, assim, que toda essa discussão tem a mesma raiz: as relaçóes desiguais entre os gêneros, desde os primórdios da evolução humana até os dias de hoje e que está presente na história das violações (Vigarello, 1998). A extensa bibliografia sobre violência de gênero está centrada na dominação masculina sobre as mulheres (Faleiros, 2007), e isso acaba por impactar a produção acadêmica. Nas sociedades historicamente machistas e religiosas, como a brasileira (Vigarello, 1998), a violência de gênero estrutura-se social, cultural, econômica e politicamente com base na concepção de que os seres humanos estão divididos entre machos e fêmeas, correspondendo a cada sexo determinados lugares, papéis, status e poderes desiguais na vida privada e na pública, na família, no trabalho e na política. $\mathrm{O}$ mesmo raciocínio vale para o perfil e evolução das demandas sobre o tema da pesquisa.

Diante do exposto, a presente pesquisa objetiva mapear sistematicamente a literatura sobre os agressores sexuais de crianças e adolescentes, discutindo questões de gênero a partir das características dos participantes presentes nos trabalhos científicos.

\section{Método}

\section{Revisão Sistemática da Literatura}

A revisão sistemática da literatura apresentou-se como um método eficaz de mapeamento e sistematização da produção científica sobre os agressores sexuais de crianças e adolescentes com a finalidade exploratória, permitindo conhecer os estudos que destacam as relações de gênero com base nas características dos participantes. Esse método propõe um tratamento estatístico dos dados dos estudos científicos por meio de uma busca sistemática e vem sendo amplamente utilizada por pesquisadores em todo o mundo (Lopes \& Fracolli, 2008) como forma de apreender e sumarizar os estudos sobre determinado tema.

Para Sampaio e Mancini (2007), as conclusóes presentes ou em estudos de determinado tema são mais robustas quando se consegue demonstrar que diferentes estudos investigam as mesmas características e fornecem dados que suportam constatações semelhantes. Nesse sentido, a revisão sistemática é o método mais adequado e atual para resumir e sintetizar evidências, bem como 
para comprovar a eficácia e os efeitos de intervenções realizadas para explorar determinado tema, auxiliando na orientação para investigação futura (Lopes \& Fracolli, 2008), como é o caso deste artigo. A revisão sistemática da literatura (RSL) focaliza uma questão claramente formulada que usa métodos sistemáticos e explícitos para identificar, selecionar e apreciar criticamente pesquisas primárias relevantes (Khan, Riet, Glanville, Sowden \& Kleijnen, 2001). Esse método sistemático é usado para evitar viés e possibilitar uma análise mais objetiva dos resultados, facilitando uma síntese conclusiva sobre os trabalhos publicados (Silva, 2009).

Por meio da pesquisa, realizou-se o levantamento de produção científica de estudos localizados no Periódico CAPES (Coordenação de Aperfeiçoamento de Pessoal de Ensino Superior) visto que essa base de dados eletrônicos contempla todos os periódicos científicos relevantes publicados nas línguas inglesa, espanhola e portuguesa. Os descritores em português utilizados para o levantamento foram: agressor sexual, pedófilo, aliciador, abusador sexual, traficante sexual, perpetrador sexual, angariador sexual, sequestrador sexual, estuprador e molestador sexual; importantes por estarem presentes em estudos escritos nesse idioma. Foram realizadas 10 buscas, pelas quais foram identificados 1.303 artigos, dos quais 1.071 foram descartados, 82 eram títulos repetidos. Ao final, foram 150 artigos selecionados com base nos critérios de inclusão e exclusão apresentados a seguir.

\section{Critérios de inclusão e exclusão}

Os critérios de inclusão foram: artigos científicos completos e indexados em qualquer ano, em todas as áreas e bases do Periódico CAPES, e artigos em três idiomas: português, inglês e espanhol. Enquanto os critérios de exclusão adotados foram: literatura cinzenta, pesquisas que envolvessem violência sexual em adultos e idosos, artigos relacionados a animais não humanos e estudos que abrangessem diagnóstico de Doença Sexualmente Transmissível (DST). Este último descritor foi excluído, pois os artigos que surgiram na busca enfatizavam sobre a DST e não sobre os agressores sexuais.

\section{Procedimento}

\section{Coleta de dados}

As buscas ocorreram no período de 3 de julho a 8 de setembro de 2012. A partir de uma busca sistemática, a revisão da literatura ocorreu em etapas sequenciais. A primeira fase se deu pelo levantamento dos descritores que pudessem atender 
aos objetivos da pesquisa. A segunda se caracterizou pela busca dos descritores no site do Periódico CAPES, seguindo os critérios preestabelecidos, como o levantamento dos títulos e dos resumos dos trabalhos encontrados, conforme afinidade com o tema investigado. A terceira etapa se deu pelos arquivamentos dos artigos encontrados, sendo estes armazenados em pastas do programa Windows Seven por ordem de busca; na quarta, criou-se uma planilha no programa de computação Excel com as variáveis preestabelecidas, gerando-se, assim, um banco de informaçōes sobre os artigos. A quinta fase foi marcada pela inserção dos artigos selecionados no banco de dados, seguida pela última etapa que compreendeu a análise dos dados com base em um procedimento descritivo, inferencial e estatístico, com o qual foi possível apresentar os resultados por meio de tabelas e frequência com dados em percentuais.

\section{Análise de dados}

Os dados foram analisados considerando-se as pesquisas empíricas e os estudos teóricos que foram organizados em dois momentos:

a) identificação quantitativa do ano de publicação, idioma de origem (idioma com o qual o artigo foi originalmente escrito), descritores, estudos nacionais e internacionais, e periódicos (indicou-se a revista em que o trabalho foi publicado); e

b) as características do estudo: formas de abordar o tema, classificação da pesquisa segundo os objetivos da pesquisa, quanto aos procedimentos técnicos, população-alvo do estudo empreendido (foram registradas as características das amostras descritas nos trabalhos empíricos analisados), como gênero, grupo etário e atos violentos citados nos trabalhos.

Para identificar os trabalhos segundo a característica da condição de gênero dos participantes desses estudos, elaboraram-se três categorias:
a) trabalhos exclusivamente com vítimas;
b) trabalhos exclusivamente com agressor;
c) trabalhos com vítima/agressor.

Para os artigos que não apresentaram as informações investigadas, a categoria de análise foi definida como não especificada (não se aplica). 


\section{Resultados e discussão}

Caracterização geral dos artigos: frequência de distribuição anual, idiomas, descritores, publicações nacionais e internacionais e periódicos

Do total de 150 trabalhos selecionados, 86\% ( $\mathrm{n}=129)$ eram pesquisas empíricas, enquanto $14 \%(\mathrm{n}=21)$ consistiam em trabalhos teóricos. A distribuição conforme característica do estudo demonstra a prevalência de trabalhos com as vítimas (69\%), totalizados em 103 artigos; os estudos com agressores sexuais somam 33 trabalhos, isto é, 22\%, e apenas 14 (9\%) pesquisas correspondem ao estudo com vítima/agressor. A relação das características do estudo com a natureza das pesquisas é demonstrada da seguinte forma: estudos empíricos com vítimas representam $91 \%$, e $9 \%$ são os teóricos. Já nos estudos com agressor sexual, $70 \%$ são empíricos e $10 \%$, teóricos. Nos trabalhos com vítima/agressor, vê-se que $86 \%$ são empíricos e $14 \%$ são teóricos. Os dados demonstram que as pesquisas empíricas são predominantes sobre as teóricas nas três categorias de análise.

\section{Distribuição dos trabalhos por ano de publicação}

Identificado o volume de trabalhos em cada base específica, os artigos foram quantificados por ano de publicação. Encontraram-se artigos publicados entre os anos de 1988 a 2012, sendo que houve maior concentração das publicações nos anos de 1995 e 2011, quando foram publicados 9\% de trabalhos sobre o tema em cada um desses anos. No ano de 1999, nota-se uma diminuição do percentual, pois do total de artigos quantificados, $7 \%$ têm a publicação no mencionado ano e 6\%, em 1996. Para uma análise mais detalhada, os estudos foram categorizados em períodos com cinco anos de intervalo de tempo, ou seja, de 1988 a 1992 (14\%), de 1993 a 1997 (28\%), de 1998 a 2002 (21\%), de 2003 a 2007 (12\%) e de 2008 a 2012 (25\%). Pode-se constatar um aumento na produção de artigos entre 1993 e 1997 em relação ao primeiro período, porém se pode dizer que, nos demais intervalos de tempo, houve uma distribuição equitativa.

\section{Distribuição dos trabalhos por idioma e publicações nacionais e internacionais}

Quanto à distribuição dos artigos por idiomas, identificou-se que $76 \%$ das pesquisas publicadas estavam em inglês, $13 \%$ foram publicadas em português e $11 \%$, em espanhol. Na correlação das características do estudo com o idioma, temse o seguinte cenário: trabalhos com vítimas cujo idioma é o inglês representaram 
$75 \%$, além de $13 \%$ em português e em espanhol. Entre os trabalhos com agressor, $79 \%$ foram publicados em inglês, $15 \%$ em português e $6 \%$ em espanhol. No que se refere às pesquisas com vítima/agressor, o idioma inglês apareceu com $79 \%$, seguido do espanhol, com 14\%; e, por último, $7 \%$ em português. Com isso, percebe-se que os trabalhos com agressores publicados em português ocorrem em maior percentual quando comparados às pesquisas realizadas com vítimas no mesmo idioma, apesar da diferença entre tais categorias ser pequena, isto é, quase proporcional. Porém, quando se analisa o volume de trabalhos com vítimas (69\%), percebe-se que a diferença é maior e predominante em relação aos agressores $(29 \%)$.

Dos trabalhos selecionados, $86 \%$ eram publicações internacionais e $14 \%$, estudos nacionais. Nos trabalhos com vítimas, $87 \%$ eram internacionais e $13 \%$, nacionais. Enquanto que, dos artigos sobre o agressor sexual, $79 \%$ se tratavam de produções internacionais e $21 \%$ eram publicaçôes nacionais. Os trabalhos com vítima/agressor somaram $93 \%$ como sendo publicações internacionais e $7 \%$, nacionais. Mesmo com os descritores no idioma português, verificou-se que a produção internacional se sobressaiu, talvez pelo fato de que essas produções foram escritas em inglês e, ou, em países de língua inglesa, correspondendo, assim, um conteúdo expressivo sobre o tema. Os dados corroboram os achados de Allard-Dansereau et al. (1997) e Craissatti \& McClurg (1997) sobre a ampla produção internacional acerca do tema em questão, sugerindo que a produção nacional, apesar de crescente, ainda é limitada.

\section{Descritores com maior volume de publicações}

Quanto aos artigos encontrados por descritores pesquisados, o termo perpetrador apresentou maior frequência (47\%), seguido pelos descritores abusador sexual (25\%), molestador (16\%), agressor sexual (6\%), pedófilo $(5 \%)$ e estuprador $(1 \%)$, sendo que os demais descritores não obtiveram nenhum registro. $\mathrm{Na}$ análise dos descritores comparados ao ano de publicação, estipulouse o intervalo de cinco anos conforme a tabela 1 . 
Tabela 1. Demonstrativo dos descritores em intervalo de cinco anos

\begin{tabular}{lcccccc}
\hline \multicolumn{1}{c}{ Descritores } & $1988 / 1992$ & $1993 / 1997$ & $1998 / 2002$ & $2003 / 2007$ & $2008 / 2012$ & Total \\
\hline Abusador sexual & $2 \%(4)$ & $11 \%(16)$ & $3 \%(5)$ & $5 \%(7)$ & $4 \%(6)$ & $25 \%(38)$ \\
Agressor sexual & $0,7 \%(1)$ & - & $0,7 \%(1)$ & $1,3 \%(2)$ & $3 \%(5)$ & $5,7 \%(9)$ \\
Estuprador & - & - & - & $0,7 \%(1)$ & - & $0,7 \%(1)$ \\
Molestador & - & $3 \%(5)$ & $1,3 \%(2)$ & - & $11 \%(16)$ & $15,3 \%(23)$ \\
Pedófilo & $0,7 \%(1)$ & $0,7 \%(1)$ & $1,3 \%(2)$ & $1,3 \%(2)$ & $1,3 \%(2)$ & $5,3 \%(8)$ \\
Perpetrador & $11 \%(16)$ & $13 \%(19)$ & $14 \%(21)$ & $4 \%(6)$ & $6 \%(9)$ & $48 \%(71)$ \\
Total & $14,4 \%(22)$ & $27,7 \%(41)$ & $20,3 \%(31)$ & $12,3 \%(18)$ & $25,3 \%(38)$ & $100 \%(150)$ \\
\hline
\end{tabular}

Fonte: elaborado pelos autores.

De acordo com os dados da tabela 1, o descritor perpetrador, comparado aos demais descritores, apareceu com maior frequência entre os anos de 1998 e 2002, o que demonstra uma prevalência desse termo nos trabalhos sobre violência sexual contra crianças e adolescentes na atualidade. $\mathrm{O}$ termo abusador sexual também apresentou uma frequência alta entre 1993 e 1997, enquanto que molestador ficou restrito aos anos de 2008 a 2012, quando comparado aos demais.

Os significados dos descritores utilizados nesta pesquisa, apesar de se referirem a atos violentos, geralmente, apresentam distinções claras na sua forma semântica, aspecto percebido com base na etimologia e do significado. Nessa direção, a etimologia da palavra abusador sexual vem "rad. do part. abusado + -or", aquele que vai além do permitido e apresenta um conceito voltado para os aspectos social, moral, ético, pois revela a conotação de algo que é proibido, mas aceitável.

Há, ainda, descritores que remetem a uma conotação para o aspecto criminal, por exemplo: "agressor" que vem do latim "aggréssor,óris o que acomete", aquele que ataca e agride; "estuprador" tem na sua etimologia "stuprátor,óris sedutor, corruptor", relacionado àquele que comete crime de estupro; e "perpetrador" "perpetrátor,óris 'id.", aquele que comete crime e delito. Apesar de a palavra "estuprador" ter na sua origem a conotação de sedutor, hoje e no contexto das sociedades ocidentais, ela está relacionada ao delito criminal hediondo.

Além deste, dois outros termos apresentam uma conotação voltada para a área da saúde: "molestador" "rad. do part. molestado + -or", relacionado a causar moléstia, atingir, fazer mal, e a palavra "pedófilo" que, etimologicamente, vem de "ped(o)- + filo", aquele que sente a impulsão e a pratica. Ambos remetem a conceitos voltados para a área da saúde. 
De maneira geral, na discussão sobre acepção dos termos pesquisados, podese dizer que alguns deles apresentam uma expressão semântica diferente da que se utiliza hoje em dia. Ou seja, embora cada termo tenha o significado determinado com base na etimologia, este apresenta, em cada conjuntura, um sentido diferente, dependendo diretamente do contexto. A busca da etimologia das palavras revelou que a conotação dada ao termo diz respeito ao objetivo da pesquisa, que prevê como o agressor é abordado no trabalho e com que significado foi abordado no estudo.

\section{Frequência de trabalhos encontrados por revistas científicas}

A revista "Child Abuse \& Neglect" apresentou 65\% dos artigos publicados com os referidos descritores, e os demais periódicos localizados apresentaram um $1 \%$ para cada periódico. O elevado percentual de artigos publicados nessa revista talvez se justifique pela própria característica da linha editorial da revista que dá ênfase à proteção à criança por formas de violência, coadunando pesquisadores de várias áreas, como serviço social, saúde, saúde mental e os sistemas de Justiça. Além disso, a linha editorial abarca uma diversidade de trabalhos que pesquisam distintos contextos: vida quotidiana, casas, creches, escolas, parques infantis, clubes de jovens, centros de saúde, locais de culto, entre outros, daí a alta frequência de trabalhos publicados nessa revista.

Caracterização da natureza dos trabalhos e da população-alvo das pesquisas empíricas em termos de grupo etário e gênero

\section{Natureza dos trabalhos}

Do total de trabalhos empíricos ( $\mathrm{n}=129), 78 \%$ concentraram-se nas pesquisas quantitativas, $9 \%$ corresponderam a pesquisas quantitativas/qualitativas, e 5\% eram qualitativas no que se refere aos trabalhos com vítimas. Nos estudos sobre os agressores, $64 \%$ consistiram em pesquisas quantitativas e $6 \%$, em pesquisas qualitativas. Em se tratando de pesquisas com vítima/agressor, a natureza do trabalho em $79 \%$ dos artigos era quantitativa e, em $7 \%$, era qualitativa. A complexidade do tema e a própria natureza da pesquisa qualitativa, que requer, muitas vezes, a triangulação de métodos e fontes de composição, tornando-a ainda mais difícil de ser realizada (Bogdan \& Bikle, 1994), desencorajam e limitam bastante os estudos com agressores sexuais, aspecto demonstrado pelos dados. Nesse caso, um método que possibilite a triangulação parece ser o mais ideal quando se estuda o fenômeno da violência sexual, sobretudo em trabalhos que busquem estudar as características biopsicossociais dos agressores sexuais. 
Ao se analisarem os objetivos das pesquisas revisadas, observou-se que os trabalhos com vítimas de agressão sexual encontravam-se definidos da seguinte forma: $78 \%$ eram descritivos, $15 \%$ foram considerados exploratórios e $8 \%$ caracterizavam-se como explicativos. Já no universo dos agressores sexuais, 67\% referiam-se a estudos descritivos, $21 \%$ foram definidos como artigos explicativos e $12 \%$ tinham um caráter exploratório, ao passo que, com vítima/agressor, $79 \%$ tinham propósitos descritivos e $21 \%$ eram explicativos.

Quanto aos procedimentos da pesquisa, nos trabalhos exclusivamente com vítimas, $70 \%$ foram de levantamento/survey, 10\% tinham cunho bibliográfico, $10 \%$ utilizaram procedimento documental, $5 \%$ eram experimental, $4 \%$ se configuravam como estudos de caso e $2 \%$ eram ex post facto. Considerandose os estudos com agressores, observou-se que o levantamento/survey foi o procedimento com maior ocorrência, tendo sido utilizado em $58 \%$ das pesquisas analisadas, enquanto 33\% foram bibliográficas e $9 \%$ das análises correspondem a estudos de caso. Passando-se para a análise dos estudos com vítima/agressor, o levantamento/survey também é o procedimento mais utilizado, haja vista ocorrer em 50\% dos artigos; em seguida, têm-se os procedimentos documentais, com $29 \%$, as pesquisas bibliográficas, com $14 \%$, e aqueles considerados como estudos de caso, $\operatorname{com} 7 \%$.

Com base nos dados apresentados, é possível afirmar que os estudos revisados estão apoiados em levantamentos, pois a própria natureza do trabalho possibilita, por exemplo, o uso tanto de instrumentais padronizados como de fontes documentais, diferentemente dos estudos de caso e das pesquisas mais qualitativas, os quais exigem um contato mais "face-to-face" bem como um corte temporal e espacial de determinado fenômeno.

No caso do agressor sexual, isso representa uma mudança na metodologia, uma vez que é necessário um conjunto de características para compreendê-lo, tais como ambiente de pesquisa natural como fonte direta de dados, o pesquisador como instrumento fundamental, o caráter descritivo e o levantamento do significado que as pessoas dão aos aspectos pessoais, sociais e culturais. Dessa forma, podese perceber que as pesquisas cujo procedimento é o estudo de casos são minoria. Isso demonstra que a forma como o agressor sexual tem sido compreendido não considera a dimensão biopsicossocial, fazendo com que as pesquisa de levantamento sejam mais utilizadas por conseguirem caracterizar o fenômeno de maneira geral, sem, contudo, discutir as trajetórias de desenvolvimento e o papel das características pessoais do agressor sexual de crianças e adolescentes. 


\section{Caracterização da população-alvo das pesquisas empíricas}

No intuito de se explorarem os dados sobre o agressor sexual, os índices foram organizados conforme a idade dos participantes, criando-se categorias de grupo etário, isto é, criança ( 0 a 12 anos), adolescente (13 a 18 anos) e adulto (19 anos em diante), relacionando-se com o gênero dos participantes e as características do estudo, conforme apresentado na tabela 2 .

Tabela 2. Demonstrativo das características do estudo relacionadas com sexo e grupo etário

\begin{tabular}{|c|c|c|c|c|c|}
\hline Característica do estudo & $\mathbf{F}$ & $M$ & $\mathrm{~F} / \mathrm{M}$ & NA & Total \\
\hline \multicolumn{6}{|l|}{ Vítima } \\
\hline Criança & $4 \%(4)$ & $1 \%(1)$ & $14 \%(15)$ & - & $19 \%(20)$ \\
\hline Adolescente & $2 \%(2)$ & - & $6 \%(6)$ & - & $8 \%(8)$ \\
\hline Adulto & $15 \%(15)$ & $2 \%(2)$ & $22 \%(23)$ & - & $39 \%(40)$ \\
\hline Criança/adolescente & $1 \%(1)$ & - & $8 \%(8)$ & - & $9 \%(9)$ \\
\hline Adolescente/adulto & - & - & $2 \%(2)$ & - & $2 \%(2)$ \\
\hline Não informado & $0,7 \%(1)$ & $0,7 \%(1)$ & $9 \%(9)$ & & $11 \%(11)$ \\
\hline Não se aplica & - & - & - & $11 \%(10)$ & $11 \%(10)$ \\
\hline Todos & $0,7 \%(1)$ & - & - & - & $1 \%(1)$ \\
\hline \multicolumn{6}{|l|}{ Agressor } \\
\hline Adolescente & - & $3 \%(1)$ & $3 \%(1)$ & - & $6 \%(2)$ \\
\hline Adulto & $6 \%(2)$ & $40 \%(13)$ & - & - & $46 \%(15)$ \\
\hline Adolescente/adulto & $3 \%(1)$ & $3 \%(1)$ & - & - & $6 \%(2)$ \\
\hline Não informado & $3 \%(1)$ & $3 \%(1)$ & - & - & $6 \%(2)$ \\
\hline Não se aplica & - & - & - & $36 \%(10)$ & $36 \%(10)$ \\
\hline \multicolumn{6}{|l|}{ Vítima/agressor } \\
\hline Criança & - & - & $7 \%(1)$ & - & $7 \%(1)$ \\
\hline Adulto & & - & $1 \%(1)$ & - & $7 \%(1)$ \\
\hline Criança/adolescente & - & - & $29 \%(4)$ & - & $29 \%(4)$ \\
\hline Criança/adulto & - & - & $7 \%(1)$ & - & $7 \%(1)$ \\
\hline Adolescente/adulto & - & - & $7 \%(1)$ & - & $7 \%(1)$ \\
\hline Não informado & - & - & $14,5 \%(2)$ & - & $14,5 \%(2)$ \\
\hline Não se aplica & - & - & - & $14,5 \%(2)$ & $14,5 \%(2)$ \\
\hline Todos & - & - & $14 \%(2)$ & - & $14 \%(2)$ \\
\hline Total & 28 & 21 & 76 & 25 & $100 \%(150)$ \\
\hline
\end{tabular}

Nota: $F$ = feminino; $M$ = masculino; $F M=$ feminino/masculino; $N A$ = não se aplica.

Fonte: elaborado pelos autores.

Quando se trata de trabalhos com vítimas, os dados concentraram-se nos grupos etários crianças e adultos, com ênfase em estudos com ambos os gêneros. Ao mesmo tempo, os trabalhos com adultos envolvem participantes em maior 
número do gênero feminino. Além disso, os trabalhos com vítimas apresentaram um baixo escore de estudo com vítimas do sexo masculino. Conforme sinalizado por Junior-Pinto (2005), os trabalhos sobre violência sexual contra crianças e adolescente estão concentrados nas vítimas do sexo feminino.

Quanto aos dados sobre os trabalhos com agressor, o escore al to está concentrado em trabalhos com adultos do gênero masculino. Tais dados corroboram o estudo de Williams (2012), o qual ressalta que os trabalhos científicos sobre agressores mulheres ainda são insuficientes. Essa tese é também confirmada por Huss (2011), cujas investigações com agressores sexuais concentram-se no sexo masculino.

Outra forma de explorar os dados da revisão sistemática foi a relação do ato violento identificado no estudo com o sexo dos participantes, conforme a tabela 3. Os atos foram analisados com base no número de vezes que apareceram, sendo associados ou não a outros atos. Vale ressaltar que, em determinada pesquisa, apareceram vários atos concomitantes e, em outros, somente um tipo dele.

Tabela 3 - Demonstrativo dos tipos de atos violentos abordados nos objetivos da pesquisa relacionado às características do estudo e ao sexo

\begin{tabular}{|c|c|c|c|c|c|c|c|c|c|c|}
\hline \multirow{2}{*}{ Atos violentos } & \multicolumn{3}{|c|}{ Agressor } & \multicolumn{3}{|c|}{ Vítima } & \multicolumn{3}{|c|}{ Vítima/agressor } & \multirow[t]{2}{*}{ Total } \\
\hline & $\mathrm{F}$ & M & $\mathrm{F} / \mathrm{M}$ & $\mathrm{F}$ & M & $\mathrm{F} / \mathrm{M}$ & $\mathrm{F}$ & M & $\mathrm{F} / \mathrm{M}$ & \\
\hline Abuso físico & - & - & - & 1 & - & 13 & - & - & 1 & 15 \\
\hline Abuso psicológico & - & - & - & - & - & 2 & - & - & - & 2 \\
\hline Abuso sexual & 2 & 11 & 1 & 23 & 3 & 50 & - & 1 & 10 & 101 \\
\hline Assédio sexual & - & - & - & - & 1 & 1 & - & - & - & 2 \\
\hline Ato libidinoso & - & 1 & - & - & - & - & - & - & - & 1 \\
\hline Coerção sexual & - & - & - & - & - & 2 & - & - & - & 2 \\
\hline Estupro & - & 3 & - & 1 & - & 2 & - & - & - & 6 \\
\hline Exploração sexual & - & 1 & - & - & - & - & - & - & - & 1 \\
\hline Incesto & - & - & - & - & - & 1 & - & - & 2 & 3 \\
\hline Infanticídio & - & - & - & - & - & 1 & - & - & - & 1 \\
\hline Maus-tratos & 2 & - & - & - & - & 5 & - & - & - & 7 \\
\hline Negligência & 1 & - & - & - & - & 3 & - & - & - & 4 \\
\hline Não se aplica & - & - & 2 & - & - & 1 & - & 2 & - & 5 \\
\hline Total & 5 & 16 & 3 & 25 & 4 & 81 & - & 3 & 13 & 150 \\
\hline
\end{tabular}

Nota: os valores são dados absolutos; $F=$ feminino; $M=$ masculino; $F M=$ feminino/masculino; NA = não se aplica.

Fonte: elaborado pelos autores. 
O abuso sexual foi o ato que mais apareceu nos estudos, com 101 registros, seguido pelo abuso físico, com 15 citações. Nos estudos com vítimas, os dados mostraram que 73 trabalhos referiram abuso sexual como principal ato, dos quais 23 foram praticados contra mulheres, 3 contra homens e 50 envolviam vítimas de ambos os gêneros. Nos trabalhos com agressor sexual, o abuso sexual foi referido em 14 estudos, sendo 2 com mulheres, 11 com homens, e 1 representando ambos os gêneros.

\section{Conclusões}

De maneira geral, os resultados mostraram que a maior frequência de trabalhos sobre violência sexual contra crianças e adolescentes está localizada nos estudos com vítimas, tanto nas pesquisas nacionais quanto nas internacionais. Apesar dos termos de busca estarem todos em português, verificou-se que a maioria dos trabalhos se encontrava em inglês e foram publicados em periódicos de circulação internacional.

Outro ponto levantado é quanto aos trabalhos exclusivamente com vítimas, nos quais o gênero que se sobressaiu foi o feminino, oposto ao dado do agressor cujo gênero é, predominantemente, masculino. O cenário científico encontrado nesses artigos demonstrou a necessidade de realização de trabalhos com vítimas do gênero masculino, dada a baixa produção acadêmica, além da necessidade de se compreender como os processos biopsicossociais se organizam em torno do agressor sexual que toma como alvo meninos, o que contribuiria no processo de intervençôes, nas práticas sociais e nas políticas públicas.

Os resultados sobre as características dos participantes dos estudos analisados mostraram que, nos trabalhos exclusivamente com os agressores sexuais, o gênero masculino obteve maior percentual. Esse resultado pode ter duas explicações possíveis: a primeira, de que a população feminina não tem sido denunciada e, portanto, há um baixo registro da violência sexual com agressoras mulheres; a segunda, o limitado acesso às mulheres que cometeram o ato, ocasionando, assim, uma baixa produção sobre o tema. Ressalta-se que é necessário um maior número de pesquisas com mulheres agressoras na tentativa de se entender e de se compreender o porquê dessa desproporção entre homens e mulheres agressores.

Esta pesquisa, portanto, contribuiu a partir do momento em que traz à luz a discussão sobre a necessidade de um olhar para os agressores sexuais, principalmente quando aponta a necessidade de estudos que possibilitem a investigação a fundo dos aspectos biopsicossociais característicos dos agressores e de pesquisas empíricas de cunho qualitativo que permitam a aproximação do fenômeno. 
Por fim, apontam-se as limitações desta pesquisa: o uso de descritores em português, o que ressalta a necessidade de inserir os termos em inglês e a busca avançada nas bases científicas de maneira que se possam cruzar descritores envolvendo a população e as características do que se quer investigar. Dessa forma, fica a sugestão para que pesquisas sobre trabalhos com agressores sexuais sejam realizadas a partir de critérios mais restritos, aumentando-se os descritores como forma de melhor correlacionar palavras ao tema e pesquisas que levantem dados sobre os trabalhos relacionados a métodos de intervenção e instrumentos de avaliação com essa população específica.

\section{Referências}

Aded, N. L. O., Dalcin, B. L. G. S., Moraes, T. M. \& Cavalcanti, M. T. (2006). Abuso sexual em crianças e adolescentes: revisão de 100 anos de literatura. Revista de Psiquiatria Clínica, 33 (4), 204-213. Recuperado a partir de http:// www.scielo.br/pdf/rpc/v33n4/a05v33n4

Allard-Dansereau, C., Haley, N., Hamane, M. \& Bernard-Bonnin, A. C. (1997). Pattern of child sexual abuse by young aggressors. Child Abuse and Neglect, 21 (10), 965-974.

Almeida, A. C. E. P. (2003). Abuso sexual contra crianças: crenças sociais e discursos da Psicologia. (Dissertação de Mestrado). Universidade do Minho, Portugal.

Assis, S. G. (2007). A adolescente e a violência. In S. R. Taquette (Org.), Violência contra a mulher adolescente/jovem. (pp. 25-29). Rio de Janeiro: EdUERJ.

Barbosa, T. M., Macedo, R. M. S., Melo, C. M. S. \& Piola, M. A. G. (2010). Violência sexual contra crianças e adolescentes e os perpetradores. Revista do Laboratório de Estudos da Violência da Unesp, 6 (6), 43-56. Recuperado a partir de http://www2.marilia.unesp.br/revistas/index.php/levs/article/ viewFile/1126/1014.

Bogdan, C. R. \& Bikle, S. K. (1994). Investigação qualitativa em Educação: uma introdução às teorias e aos métodos. Porto: Porto Editora.

Brewster, A. L., Nelson, J. P., Hymel, K. P., Colby, D. R., Lucas, D. R. McCanne, T. R. \& Milner, J. S. (1998). Victim, perpetrator, family, and incident characteristics of 32 infant maltreatment deaths in the United States Air Force. Child Abuse and Neglect, 22 (2), 91-101. Recuperado a partir de http://www. ncbi.nlm.nih.gov/pubmed/9504212 
Christiansen, A. R. \& Thyer, B. A. (2002). Female sexual offenders: A review of empirical research. Journal of human Behavior in the Social Environment, 6 (3), 1-15. Recuperado a partir de http://www.scie-socialcareonline.org.uk/ profile.asp?guid=26157696-1fbf-444a-af6d

Costa, H. O. G., Cordeiro, T. R. F., Kalil, M. E. X. \& Brandão, A. E. (2007). Violência em Salvador e as formas de enfrentamento. Revista Vera Cidade, 2 (2), 2-15.

Costa, M. C. O. , Carvalho, R. C., Bárbara, J. F. R. S., Santos, C. A. S. T., Gomes, W. A., Sousa, H. L. de (2007). O perfil da violência contra crianças e adolescentes, segundo registros de conselhos tutelares: vítimas, agressores e manifestações de violência. Ciência e Saúde Coletiva, 12 (5), 1129-1141. Recuperado a partir de http://www.scielosp.org/scielo.php? pid=s14131232007000500010\&script=sci_arttext

Craissatti, J. \& McClurg, G. (1997). The Challenge Project: perpetrators of child sexual abuse in South East London. Child Abuse and Neglect, 20 (11), 1067-1077. Recuperado a partir de http://www.sciencedirect.com/science/ article/pii/0145213496000956.

Dragowski, E. A., Rio, M. R. S. \& Sandigorsky, A. L. (2011). Childhood Gender Identity... Disorder? Developmental, cultural and diagnostic concerns. Journal of Counseling and Development, 89, 360-366.

Faleiros, E. (2007). Violência de gênero. In S. R. Taquette (Org.), Violência contra a mulher adolescente/jovem. (pp. 61-66). Rio de Janeiro: EdUERJ.

Green, S. (2005). Systematic reviews and meta-analysis. Singapore Medical Journal, 46 (6), 270-274. Recuperado a partir de http://xa.yimg.com/kq/ groups/18751725/1818949317/name/Systematic.

Habigzang, L. F., Koller, S. H., Azevedo, G. A. \& Machado, P. X. (2005). Abuso sexual infantil e dinâmica familiar: aspectos observados em processos jurídicos. Psicologia Teoria e Pesquisa, 21 (3), 341-348. Recuperado a partir de: http:// www.scielo.br/pdf/ptp/v21n3/a11v21n3

Hohendorff, J. V., Bavaresco, P. D., Habgzang, L. F. \& Koller, S. H. (2012). Abuso sexual contra meninos. In L. F. Habigzang \& S. H. Koller (Orgs.), Violência contra crianças e adolescentes: teoria, pesquisa e prática. (pp. 107-122). Porto Alegre: Artmed. 
Huss, M. (2011). Psicologia Forense: pesquisa, prática clínica e aplicações. Porto Alegre: Artmed.

Junior-Pinto, A. A. (2005). Violência sexual doméstica contra meninos: um estudo fenomenológico. São Paulo: Vetor.

Khan, K., Riet, G., Glanville, J., Sowden, A. J. \& Kleijnen, J. (2001). Undertaking systematic reviews of research on effectiveness: CRD's guidance for those carrying out or commissioning reviews. Nova York: Centre for Reviews and Dissemination.

Krug, E. G., Dahlberg, L. L., Mercy, J. A., Zwi, A. B. \& Lozano, R. (2002). World report on violence and health. Geneva: World Health Organization.

Lopes, A. L. M. \& Fracolli, L. A. (2008). Revisão sistemática de literatura e metassíntese qualitativa: considerações sobre sua aplicação na pesquisa em enfermagem. Texto e Contexto de Enfermagem, 17 (4), 771-778. Recuperado a partir de http://www.scielo.br/scielo.php?script=sci_ arttext\&pid=S0104-07072008000400020

Marques, H. M. V. (2005). A voz do abusador: aspectos psicológicos dos protagonistas de incesto. (Dissertação de Mestrado). Universidade Católica de Brasília, Brasília.

Martins, C. B. G. \& Jorge, M. H. P. M. (2010). Abuso sexual na infância e adolescência: perfil das vítimas e agressores em município do sul do Brasil. Texto e Contexto Enfermagem, 19 (2), 246-255. Recuperado a partir de http:// www.producao.usp.br/bitstream/handle/BDPI/12546/art_JORGE_Abuso_ sexual_na_infancia_e_adolescencia_perfil_2010.pdf?sequence $=1$

Morais, N. A., Santos, E. C., Moura, A. S., Vaz, M. \& Koller, S. (2007). Exploração sexual comercial de crianças e adolescentes: um estudo com caminhoneiros brasileiros. Psicologia: Teoria e Pesquisa, 23 (3), 263-272. Recuperado a partir de http://hdl.handle.net/10183/20545

Moura, A. S. (2007). A criança na perspectiva do abusador sexual. (Dissertação não publicada), Universidade Federal do Rio Grande do Sul, Porto Alegre.

Pereira, A. S., Lira, S. V. G., Xavier, E. P. \& Vieira, L. J. E. S. (2007). Produção sobre acidentes e violência apresentada em encontros de iniciação científica. Revista de Enfermagem UERJ, 15 (2), 218-22. Recuperado a partir de http:// www.facenf.uerj.br/v15n2/v15n2a10.pdf 
Phebo, L. (2007). Vigilância em saúde e a violência contra adolescentes. In S. R. Taquette (Org.), Violência contra a mulher adolescenteljovem. (pp. 31-34). Rio de Janeiro: EdUERJ.

Sampaio, R. F. \& Mancini, M. C. (2007). Estudos de revisão sistemática: um guia para síntese criteriosa da evidência científica. Revista Brasileira de Fisioterapia, 11 (1), p. 83-89. Recuperado a partir de http://www.scielo.br/ $\mathrm{pdf} / \mathrm{rbfis} / \mathrm{v} 11 \mathrm{n} 1 / 12$.pdf.

Serafim, A. P., Saff, F., Rigonatti, S. P., Casoy, I. \& Barros, D. M. (2009). Perfil psicológico e comportamental de agressores sexuais de crianças. Revista de Psiquiatria Clínica, 6(3), 105-111.

Silva, E. R. P. (2009). Métodos para revisão e mapeamento, sistemático da literatura (Projeto de Graduação). Universidade Federal do Rio de Janeiro, Rio de Janeiro.

Vigarello, G. (1998). História da violação: século XVI-XX. Portugal: Estampa.

Weber, L. N. D., Viezzer, A. P. \& Brandenburg, O. J. (2004). O uso de palmadas e surras como prática educativa. Estudos de Psicologia, 9 (2), 227-237. Recuperado a partir de http://www.scielo.br/pdf/epsic/v9n2/a04v9n2.pdf

Williams, L. C. A. (2012). Pedofilia: identificar e prevenir. São Paulo: Brasiliense. 